\title{
Descriptive Analysis About Management Of Conflict At Sma Spektrum Manado
}

\author{
Sophia Pongoh \\ Faculty of Economic, Unimaat Tondano, Minahasa-Indonesia
}

\begin{abstract}
The objective of this research is to analyze with descriptive about conflict management style at SMA Spektrum Manado.

Method of reseach is descriptive method with collect data with using the qustionaire and then to do to analyze data with procentage. The respondent are the teachers of SMA Spectrum Manado with the sum 17 teachers.

The result that we have showed : principal of school to solving conflict at school using five style of conflict management there is : competition, collaboration, compromise, avoiding and accomodation.

Key words: management conflict.
\end{abstract}

\section{Introduction}

Education is an important aspect of human life in developing quality human resources . Therefore all matters relating to the provision of education should be empowered to be able to contribute positif for success as generations of students. This will be something that is important and beneficial for the development of quality education and can be a positive contribution to nation building . Everyone is aware that education is important and has been a basic human need, therefore, government and education providers in all cedars expected to encourage constructive actions to improve the quality and productive learners .

The era of globalization with the increasingly fierce competition has penetrated all spheres of human life so that opportunities can be captured and available only achieved by those who have high creativity , innovative and persistence to continue striving for a better life. This is where the importance of educational institutions to improve itself in increasing its role so that each person or member is given an equal opportunity for achievement or demonstrated ability to perform their duties .

School is a unit of educational institutions that provide education and learning based on a predetermined level and is based on laws.By way of organization, the school requires effective management to be used in regulating all activities and resources so that all components of the school will be managed properly by trying to involve all school personnel are teachers and clerks. The activities that are being carried out and will be designed and carried out effectively and productively through the efforts of achieving the goals set so that there is unity of direction and command in realizing success .

The success in achieving the objectives of an organization in need of power and funds as well as the activities to be performed by members either individually or in groups. Thus every person has a duty and responsibility to do any work entrusted to him . Effectiveness of the organization in need of unity of direction and purpose under the command of the leadership. This is where the importance of cooperation and team work to realize the plans that have been established so expect the same vision and mission in performing tasks . Differences in perceptions of reality often appears to work processes and goals that do not achieve what is expected or not according to plan.

Every shape and purpose of any organization, there is always a dynamic life of the individuals in it that indicates that there is a dynamic organization because work processes therein. These work processes are often the beginning of the conflict due to differences of opinion or perception, the gap between desire and reality, the limited resources available, and many more sources or causes of the conflict . So many aspects that can be a cause of conflict in the organization because of the conflict in the organization can not avoidable.Everard, et al (2004) states : the absence of conflict may indicate abdication of responsibility, lack of interest or lazy thinking. This statement implies that the conflict must exist in the organization . Even Winardi (2007) stated that the conflict needs to be stimulated to raise employee morale . Management deliberately creating a climate through the competition gets bonuses, and so on .

Handoko ( 2009 ) cites the opinion that Robbins distinguish between two views of the conflict, namely : a long view of the conflict which considers ( 1 ) the conflict can be avoided, ( 2 ) conflicts caused by management mistakes in the design and management of the organization or by vandals. While the new view of the conflict, see conflict : ( 1 ) the conflict can not be avoided, ( 2 ) conflicts arise due to many reasons, including the organizational structure, different goals that can not be avoided, differences in perceptions and 
personal values and so on , ( 3 ) conflict can help or hinder the implementation of the organization's activities in varying degrees , ( 4 ) task is to manage the level of conflict management and resolution , ( 5 ) implementation of the optimal organization requires a moderate level of conflict . Last outlook indicates that a certain level of conflict in the organization needed to improve the performance of the organization, so that the conflict is not always eliminated. It is precisely on certain things needed to get something that is optimal after careful consideration and different opinions .

As one of the school organization, high school Manado Spectrum is a private school run by a variety of uniqueness also experience conflict even become a phenomenon that always happens. The conflict occurs between principals and teachers, teachers with teachers, or with the administrative staff. This is due to differences such as the status of teachers, civil servants and there is no impact on the honorarium teacher obtain the difference in funding sources available. Besides, the variation is quite high schools work with regard to the following aspects: teaching duties, teachers have different skills, social background, all of which are highly susceptible raises conflict. Therefore, the principal must have the ability to identify the types of conflict and understand the ways to handle it so as not to harm or interfere with school assignments should provide maximal service for students .

The teachers are the most important component in organizing and strategic tasks of education and learning in schools. Sanjaya ( 2010 ) suggested the roles of teachers, namely : ( 1 ) the teacher as a source of learning, ( 2 ) the teacher as facilitator, ( 3 ) the teacher as the manager, ( 4 ) the teacher as a demonstrator, ( 5 ) teachers as mentors , ( 6 ) teacher as a motivator, ( 7 ) the teacher as an evaluator. These roles indicate that the teacher has a strategic position in providing education related to the needs of the students. The task of the teacher's role is complex and highly vulnerable to conflict consciously or unconsciously influences the work patterns which require cooperation and teamwork. The pattern should work in synergy with each other instead become a source of conflict when existing policies are not in accordance with the wishes and needs of members in this case teachers. On the other hand that the role of the teacher is not effective could lead to konflict if there are teachers who do not perform the intended role or imbalance occurs in such leader. Then assignment undertaken various phenomena that can lead to conflict, example : unequal division of labor, resource sharing is unfair, awards favoritism .

Teachers need time and effort and the ability to do its job better. There are at least 4 ( four ) to be done by the teacher prior to learning, namely : preparing annual and semester programs, create a syllabus , lesson plan, formulate remedial programs and teaching, preparing guidance program ( Supardi, et al, 2009) . The things that have been put forward is not easy for teachers to be done, however, as professionals, this work is one indicator of the performance of duties of a teacher as one basis for the assessment of teacher performance by superiors (principals ). More important that this work requires knowledge, skill and perseverance of teachers to be able to do so. When this work was not able to be done by the teacher, it can be a source of conflict in schools, because it is the principal must continually evaluate the performance of duties of teachers. Thus the phenomenon of conflict in schools can not be circumvented include Spectrum High School in Manado.

Based on the explanations that have been put forward, the authors conducted a study with the title : a descriptive analysis of conflict management at Spectrum High School Manado. The formulation of the research problem is : how the implementation of conflict management styles in SMASpektrum Manado ? The experts various views about the conflict, and specifically in this study is organizational conflict where it is stated that the conflict should be handled ( handles ) so as not to interfere with the achievement of organizational goals. Therefore in this paper will be studied several styles of conflict management used the leader or manager to minimize any negative impacts of conflict and encourage conflict is constructively.Everard, et al (2004) states : the ability to handle conflict is a key factor in managerial success. This statement implies that a successful manager if it is able to handle conflict. Sometimes in order to achieve success requires change and for change could be achieved through conflict.

Wirawan (2010) stated that the conflict is one of the essence of life and human development that have diverse characteristics. This conflict is described perspktif interpersonal conflict as the conflict in an organization. In another section stated that the conflict is the opposition that is expressed in the interdependent for two or more partiesto the object of conflict, using patterns of behavior and interaction that produces output conflict conflict. Further Wirawan ( 2010) suggests some elements of conflict : ( 1 ) Process ; ( 2 ) two or more parties. ( 3 ) interdependent. ( 4 ) disagreement about obye kkonflik. ( 5 ) is expressed ; ( 6 ) patterns of behavior; $(7)$ the interaction of conflict; ( 8 ) output conflict. The indicators that have been presented show that in life, as a group within the organization is very easy to conflict. Therefore, social life everyone needs to be developed and improved as a means of fostering a sense of community, but also as a way to suppress or minimize the occurrence of conflict .

Everyone in the organization has a life interests and goals that are sometimes different from the others and may be in conflict with others so as to allow the emergence of behaviors that are considered deviant. When there are behaviors that are not appropriate to the situation indicated another person or other party, then it is 
likely to be a trigger of conflict. Thus it can be said that the phenomenon of human life is close to both the conflict arises because of personal interest let alone organization. It is therefore very important for any organization to be able to manage conflict through conflict management .

Basically conflict was caused by many things depending on the time, place and situation conflict emergence.Stoner (1992) stated that the conflict occurs because there is a difference of opinion between two or more people in the organization, because they have to divide the scarce resources or work activities, or because they have the status, purpose, or different view. This assessment shows that conflict is inevitable in organizations there is even a view that the conflict should arised. Because of that, Stoner suggested that two different views about the conflict he describes as a long view and new view. Stoner further concluded that there are four things that become a source of conflict, namely : (1) the need to divide the scarce resources; ( 2 ) the purpose of the organization is different between the work unit ; ( 3 ) the interdependence of work activities ; ( 4 ) differences in the assessment and opinion among the units. Then Wirawan (2010) identify the causes of the conflict or the sources of conflict, namely : ( 1 ) limited sources ; ( 2 ) different purposes ; ( 3 ) mutually dependent or interdependent tasks ; ( 4 ) the diversity of social systems ; ( 5 ) deference organization ; ( 6 ) the ambiguity of jurisdiction ; ( 7 ) a private person ; ( 8 ) is not worth the reward system ; 9 ) the communication is not good ; ( 10$)$ inhuman treatment. Understanding of the types of conflict and causes, management capabilities needed to identify and plan the process were based on the degree of impact of each conflict .

There are several views on the conflict as proposed Robbins and Judge (2009), namely : ( 1 ) the traditional view , ( 2 ) view of human relations ; ( 3 ) interactionist view. The traditional view, see conflict as something harmful, so every phenomenon can be dangerous. Conflicts that arise must be removed because it can damage. View of human relationships see the conflict in organizations is reasonable and nature. In this situation, a conflict that arises is not a bad thing but it can be considered as a potential, if properly managed , which in turn can affect the organization .

Interactionist view of conflict as a positive force something that should be on every parties. The insight departs from the understanding that the conflict can enhance the performance of organization.Robbins and Judge (2009; 524 ) quoting Thomas stated that the handling of the conflict has two dimensions, namely : cooperativeness and assertiveness. The five goals conflict handlers are: competing ( assertive and uncoopertive ) ), collabborating ( assertive and cooperative ), avoiding ( unassertive and uncooperative ), accomodating ( assertive and cooperative), and compromising on ( midrange on both assertiveness and cooperativeness) . Slocum and Hellriegel ( 2007) suggests that there are several dimensions that affect the conflict so that there are no conflicts are easily resolved sticking. Dimensions of conflicts are : the issue itself, the size of the risk, the continuity of interaction, the characteristics of the group of participants, the involvement of a third party .

Besides, the level of conflict in the organization will affect the pattern of settlement that will do the management. Slocum and Hellriegel ( 2007 ) suggests the level of conflict within the organization, namely : intrapersonal ( within an individuals ), interpersonal (between individuals ), intragroup ( within a group ), and intergroup (between groups ). Conflicts requires understanding, and understanding is the leadership as early as possible and then perform preventive measures in anticipation so as not to be a major problem that can interfere with the performance of organizational impact. But be aware also that sometimes there is a conflict that can be useful in promoting the spirit of the members of the task of leadership to be able to recognize these types of conflicts and subsequently manage it based on the needs of the organization and its members .

Luthans (2006 ) clustered conflicts into two groups , namely organizational conflict and conflict intraindividu, interactive. Intraindividu conflict, these conflicts occur due to several reasons that come from individuals themselves, namely : conflict due to frustration, conflict objectives, role conflict and ambiguity . Then an interactive conflict, the conflict is related to the interaction between individuals and groups as a manifestation of the dynamics of individuals and groups in an interactive. Conflict organization consists of : interpersonal conflicts and conflicts between parties. Every types and sources of conflict, suggests that every organization is always vulnerable the conflict because it needs to be able to handle the anticipated or konflik.Setiap resolve potential conflicts must be managed so as not to turn into something dangerous to individuals and organizations .

After reviewing some of the opinions of experts, then the conflict is actually divided into two types: constructive conflict and destructive conflict. Wirawan (2010) put forward constructive conflict characteristics , namely : ( 1 ) trying to resolve differences over the substance of the conflict, ( 2 ) successfully define and clarify the causes of conflict, ( 3 ) communication and intensive negotiations to clarify their respective positions , ( 4 ) tries to control emotions, anger, anxiety and stress, ( 5 ) give and take of negotiations, ( 6 ) conflict conical spiral toward compromise or collaboration, ( 7 ) and try to find a win win solution that is satisfactory to both parties involved in the conflict. Further characteristics of the proposed destructive conflict, namely : ( 1 ) polarization differences, ( 2 ) reduced cooperation, ( 3 ) conflict centered not on the substance of the conflict, ( 4) there is greater conflict spiral and rising, ( 5 ) the behavior of the opponent degrading conflict, ( 6 ) threatening behavior, ( 7 ) confrontation and threatening behavior, ( 8 ) the tension, anxiety, stress and 
aggression, ( 9 ) negotiating a minimum, ( 10 ) conflict management style competition , ( 11 ) crisis , ( 12 ) wants a win \& lose solution, ( 13 ) damage relations ( 14 ) to save face (Wirawan , 2010). The second type of conflict is actually very beneficial for everyone in interpret every phenomenon of conflict. Understanding any kind of conflict and its characteristics will facilitate the management to take actions appropriate in terms of minimizing tension or reduce behaviors that could lead to conflict. Therefore, every organization must not allow the deviant behavior or contrary to the rules and norms that apply .

Although it must be recognized that not all conflict is negative as said Newstrom (2007), namely : conflict is not all bad. It means that the conflict is also no benefit to the organization . Newstrom therefore suggests that the benefits of conflict : that people look at in order to fix stimulated approaches that lead to the best results. It can encourage creativity members with new ideas or ideas that should exellent. Because of every leader must respond to every phenomenon of conflict .

Of the studies that have been raised, it can be said that the conflict in the organization due to several factors which appointed indicators organizational conflict : ( 1 ) a scarce resource ; ( 2 ) different purposes ; ( 3 ) mutually dependent or interdependent tasks ; ( 4 ) the diversity of social systems ; ( 5 ) deference organization ; ( 6 ) the communication is not good ; ( 7 ) a private person ; ( 8 ) is not worth the reward system ; ( 9 ) inhuman treatment. This indicator is based on the opinion Stoner, Luthans, Robbins and Judge, and Wirawan . Furthermore, that these conflicts should be managed with the application of conflict management style . Conflict management styles in question are : competition, collaboration, compromise, avoidance and accommodation . Will be described in detail below.

\section{Competition Style}

Conflict management style with competition requires management to use assertiveness based on formal structures . With this style coercion principals can do to resolve the conflict . Newstrom (2007) called it controntation, where the force is trying to find a direct conflict and conduct a settlement that satisfied. Griffin and Moorhead ( 2007:402) states : accurs competition when the goals are incompatible, and the interactions are important to each party 's meeting its goals . . . . . Became the competition too important, open antagonism resulted, rules were ignored, and the competition changed to an open conflict, resulting in decreases in actual work performance. It means that the competition occurs when conflicting goals, and interactions is important for each group to find the goal. Competition becomes important,resulting from open conflict, the rules are ignored, and the competition turns toward open conflict, resulted in a decreased work performance. From this view it is very likely that competition conflict management style should be used carefully and in a very urgent so as not to harm the organization and is not detrimental to members, as conflict management efforts aimed at improving organizational performance towards the better .

\section{Collaboration Style}

Collaboration is one of the conflict management style that seeks settlement without being victimized or disadvantaged but preferred destination to be reached. Griffin and Moorhead (2007 ) states : Collaboration occurs when the interaction between groups is very important to Attainment goals, and the goals are compatible ....... Collaborative relationships can lead to new and innovative ideas and solutions to differences among the parties. It means that collaboration occurs when the interactions between groups is essential to achieving the goals and fit. Also explained that collaborative relationships can lead to new ideas and innovative solutions to the differences between the groups. This view implies that the collaborative conflict management style put the interests of the organization and the interests of members can be achieved or fulfilled . Because the style is very suitable to be used in order to bring groups involved in the conflict to see who is more important in the survival of the organization .

\section{Compromise Style}

Compromising conflict management style is more emphasis on conflict resolution settlement a win win solution. The most widely used compromise to resolve conflict and applies to any kind of conflict . Griffin and Moorhead ( 2007 ) argues : Compromise accurs when the interactions are moderately important to goal Attainment, and the goals are completely compatible Neither nor completely incompatible. In compromise situation, parties interact with others striving to Achieve goals, but they may not aggresively pursue the goal Attainment in either a competitive or collaborative manner Because the interactions are not that important to the goal Attainment. It means that a compromise occurs when the interactions are moderately important to achieve the goals and objectives there is perfect and there are less suitable. Under no circumstances compromise , groups interact with other people trying to achieve the goals, but not as aggressive as in the competitive situation or collaboration. This view implies that conflict management styles with less compromise to encourage people or groups in conflict to try to work hard as the competition and collaboration 


\section{Avoidance Style}

Avoidance conflict management style is actually less challenging because the leaders are not doing anything to manage conflict. Griffin and Moorhead (2007) states: Avoidance Occurs when an interaction is Relatively unimportant to either party's goals, and the goals are incompatible. It means that avoidance occurs when an interaction is relatively unimportant to another group goals and objectives that are at odds. This view implies that when the objectives are less important for the organization could even to generate conflict between the groups avoidance techniques deemed appropriate way to resolve the conflict.

\section{StyleAccommodation}

Conflictmanagementstyle with accommodationis the mosteasy to dobecausetrying to pleaseboth sidesof the conflict. GriffinandMoorhead(2007) states: Accomodationoccurswhenthegoalsarecompatible, but theinteractionsare notimportanttothe overallgoalConsideredattainment. It's meanthattechniqueaccommodationoccurswhengoalsareachieved in accordance, butthe interactionbetween groupsis not importantin achievingobjectives. This viewshowsthatthetechniqueisan importantpropertythatthe goal is reachedandthe groupsonlyagreewithwhatwouldbe achieved. Thus theactualaccommodationtechniquesprovide a way outthroughthe middle of theroadin a situationlikethis, the managementtried toacceptallinput/suggestions.

Wirawan(2010) summarizesthe fivestylesof conflictmanagementasin the table.

\begin{tabular}{|c|c|c|c|c|}
\hline Competition & Collaboration & Compromise & Avoiding & Accommodation \\
\hline $\begin{array}{l}\text { Argueandargue, } \\
\text { sticking tothe } \\
\text { establishment, assessing } \\
\text { theopinions andfeelings } \\
\text { ofself andopponentof } \\
\text { conflict, } \\
\text { statingclearlypositionthe } \\
\text { mselves, } \\
\text { abilityincreaseselfpower, } \\
\text { ability } \\
\text { tominimizepowerconflict } \\
\text { opponents, usinga } \\
\text { variety } \\
\text { oftacticsthataffect }\end{array}$ & $\begin{array}{l}\text { Llisten well presented } \\
\text { opponents conflict, } \\
\text { negotiating skills, } \\
\text { identifying opposing } \\
\text { opinions conflict, } \\
\text { confrontation is not } \\
\text { threatening, analyze } \\
\text { inputs, provide } \\
\text { concessions }\end{array}$ & $\begin{array}{l}\text { Negotiate, } \\
\text { listen well } \\
\text { presented } \\
\text { opponents conflict, } \\
\text { evaluate the value, } \\
\text { find a middle } \\
\text { ground, giving } \\
\text { concessions }\end{array}$ & $\begin{array}{l}\text { Ability to } \\
\text { withdraw, without } \\
\text { any ability to leave } \\
\text { something } \\
\text { unfinished, the } \\
\text { ability to rule out a } \\
\text { problem, the ability } \\
\text { to accept defeat, } \\
\text { the ability to forget } \\
\text { something hurtful }\end{array}$ & $\begin{array}{l}\text { Ability to forget about } \\
\text { yourself, the ability to } \\
\text { serve an opponent of } \\
\text { conflict, the ability to } \\
\text { comply with the orders } \\
\text { or serve opposing the } \\
\text { conflict. }\end{array}$ \\
\hline
\end{tabular}

Source:Wirawan(2010)

School is a unit of organization in which there are people, in this case teachers must work together, to work together to implement the task force based policies in education and specifically in accordance with the level of force that is high school . Various policies in schools have to be applied and implemented based on or refer to the policy of the Government district / city through the Department of Education and Culture District / City . Sometimes there are policies that do not meet the needs of teachers both individually and in relation to which often have an impact on institutional conflicts. Therefore it is the duty of the principal or the principal to be able to monitor / watching phenomena conflicts that arise or will occur and seek and find ways to seek the solution or solution / way out through conflictmanagement .

Studies on theories of conflict and conflict management control or has been proposed and is expected to serve as guidelines for principals to be able to use it in managing organizational conflict in schools . Conflict management in organizations is required to minimize the conflict that is both destructive and constructive conflict maintain that ultimately beneficial in improving organizational effectiveness. Basically everyone wants a comfortable and secure life in the organization, but that happens that conflict is always there and became a phenomenon in every organization. Therefore, the hypothesis in this study is applying the principals of conflict management styles to minimize the negative impact of conflict through strategies : competition, collaboration, compromise , avoidance and accommodation in Manado Spectrum High School.

\section{Research Methods}

The method used in this research is descriptive method with the aim to describe the conflict management styles used principals to manage the conflicts that occur in schools. Further data collection is done with the questionnaire and the data were analyzed descriptively who follow these steps: counting the number of respondents, calculate the answers and further interpret the respondents' answers. Respondents in this study were the teachers because it captured data is based on the perception of teachers, what is seen, experienced and felt by teacher. Analysis data in percentage with the formula: number of answers in the number of respondents multiplied by $100 \%$ which further given the appropriate interpretation theory study. 


\section{Results and Discussion of Research Results}

These results analyzing respondents' answers related to the use of conflict management styles of principals and the answer is based on the answers of teachers.

\section{Conflictmanagementstylecompetition.}

\begin{tabular}{|l|c|c|c|}
\hline Intensityof use & Numberof responses & Percentage & Explanation \\
\hline Always & 5 & $27,8 \%$ & \\
\hline Sometimes & 13 & $72,2 \%$ & \\
\hline Never & - & - & There is no answer \\
\hline Total & 18 & $100 \%$ & \\
\hline
\end{tabular}

From the analysis of the data there are 5 people $(27.8 \%)$ answered always, meaning that $27.8 \%$ knew that the principal always used conflict management style competition to deal with conflict, while as many as 13 people $(72.8 \%)$ answered sometimes . The percentage who answered sometimes it can be interpreted that the principal in the school it's handled intensity conflict sometimes. Thus that conflict management style competition only occasionally performed by the principal.

2. Collaborativeconflictmanagement style

\begin{tabular}{|l|c|c|c|}
\hline Response & Numberof responses & Percentage & Explanation \\
\hline Always & 16 & $88,89 \%$ & \\
\hline Sometimes & 2 & $11,11 \%$ & \\
\hline Never & - & - & There is no answer \\
\hline Total & 18 & $100 \%$ & \\
\hline
\end{tabular}

Based on the analysis of data, as many as 16 people (88.89\%) answered always and as many as 2 $((11.11 \%)$ answered sometimes, and no one answered never. Number of people who answered always is $88.89 \%$ it can be interpreted that the principal always uses the collaborative conflict management style in dealing with conflict in schools, while the answer is sometimes only two people or as many as $11.11 \%$. intensity never For no one answered.

3. Compromiseconflictmanagementstyle

\begin{tabular}{|l|c|c|c|}
\hline Intensityof use & Numberof responses & Percentage & Explanation \\
\hline Always & 10 & $55,56 \%$ & \\
\hline Sometimes & 6 & $33,33 \%$ & \\
\hline Never & 2 & $11,11 \%$ & \\
\hline Total & 18 & $100 \%$ & \\
\hline
\end{tabular}

Based on the analysis of data obtained by 10 people (55.56\%) answered always, as many as 6 people $(33.33 \%)$ responded, and sometimes as much as 2 people $(11.11 \%)$ never responded. The results of this analysis can be interpreted that the intensity of the use of conflict management style with a compromise is often used in dealing with the conflict, while the answer is sometimes there are 6 people and never 2 shows that the conflict management styles used compromise is still quite dominant principal.

4. Avoidingconflictmanagementstyle

\begin{tabular}{|l|c|c|c|}
\hline Intensityof use & Numberof responses & Percentage & Explanation \\
\hline Always & 2 & $11,11 \%$ & \\
\hline Sometimes & 12 & $66,67 \%$ & \\
\hline Never & 4 & $22,22 \%$ & \\
\hline Total & 18 & $100 \%$ & \\
\hline
\end{tabular}

Based on the analysisof datathere are2 people $(11.11 \%)$ who answeredalways, as many as 10 people $(66.67 \%)$ who answeredandsometimesas many as 4 people, or $22.22 \%$ wereneveranswered. The results ofthis analysiscan beinterpretedthat theuse ofavoidanceconflictmanagement styleby the principalonlyinintensityat timeswhile2personsor $11.11 \%$ answered alwaysandansweras many as 4 peoplewere neverused. 
Descriptive Analysis About Management Of Conflict At Sma Spektrum Manado

\section{Accommodation conflict management style}

\begin{tabular}{|l|c|c|c|}
\hline Intensityof use & Numberof responses & Percentage & Explanation \\
\hline Always & 4 & $22,22 \%$ & \\
\hline Sometimes & 14 & $77,78 \%$ & \\
\hline Never & - & - & There is no answer \\
\hline Total & 18 & $100 \%$ & \\
\hline
\end{tabular}

Based on the analysisof data, as many as4 people(22.22\%) answeredalways, as many as 14 people(77.78\%) answeredsometimes, while theintensityis neverno one answered. The results ofthis analysiscan beinterpretedthat theconflict management stylesof accommodationusedby theschool principalintensitysometimes.

Based on the researchandthe analysis of datathathave been raised, it was in high schoolthere aretwoconflict management styleof ManadoSpectrum, thatis often usedisthe collaborationandcompromise, while thecompetitionconflictmanagementstyles, avoidingandpropertyusedinintensityat times.

\section{Discussion of Research Results}

The use of conflict management style in the organization is very helpful members of the organization to improve its performance for increased organizational productivity. The fact that each institution / organization is always confronted with a problem that could turn into destructive conflict if not addressed, otherwise if handled effectively can be a constructive conflict.

Based on the data that has been presented analys result, Spectrum High School principal Manado principals implement the five styles of conflict management in managing conflict in schools with different intensities. The conflict management style or strategy are: competition, collaboration, compromise, avoidance and accommodation. Each style of conflict management is used as needed and conflict situations in order to make any destructive conflict should be minimized if possible eliminated whereas constructive conflict should be encouraged to be able to produce something useful for the progress of the organization. Furthermore, we will discuss the results of the study by the following conflict management style.

\section{Competition Conflict Management Style}

The results showed that this style is less used by the principal in managing conflict in Manado Spectrum High School. This in accordance with the opinion of Thomas and Kilmann in Wirawan (2010) which states that this style is a power-oriented style where someone would use its power to win the conflict with charges his opponent. A similar opinion was expressed Hendrick (2001) that this force pressure on yourself. This style is effective when a quick decision is needed. And this strategy to be reactionary, which is driven by a self-defense mechanism. These two arguments indicate that the conflict management style some call it competition or dominance can only be used at the time of urgency where rapid decisions to be taken with the consequences of the rules and sometimes opposing interests conflict ignored.

\section{Collaboration Conflict Management Style}

Based on the results of data analysis, this style is used in the intensity always, in dealing with conflict in Manado Spectrum High School. This result is consistent opinion of Derr ( in Wirawan , 2010) which states that collaborative conflict management style that is most preferred because : ( a) encouraging interpersonal relationships, ( b ) innovative and creative force for improvement, ( c ) increase the flow of information and feedback, and ( d ) develop a more open organizational climate, trust, risk-taking and good feelings toward integrity . This opinion is supported by the opinion of Griffin and Moorhead (2007) which states collaboration occurs when the interactions between groups is essential to achieve the goals and objectives accordingly. Also explained that collaborative relationships can lead to new ideas and innovative solutions to the differences between the groups. This style is very suitable to be used in order that the groups involved in the conflict to see things more important in the survival of the organization. Based on the opinion of the style is suited to the situation of conflict that often occurs Disma Spectrum Manado .

\section{Compromise Conflict Management Style}

Based on the results of data analysis, conflict management style includes many styles used in dealing with conflict in Manado Spectrum High School nearly equal intensity with the use of collaboration. This result is consistent with opinion of Griffin and Moorhead ( 2007) suggests : Compromise accurs when the interactions are moderately important to goal Attainment, and the goals are completely compatible Neither nor completely incompatible. In compromise situation, parties interact with others striving to Achieve goals, but they may not aggresively pursue the goal Attainment in either a competitive or collaborative manner Because the interactions are not that important to the goal Attainment. It means that a compromise occurs when the interactions are 
moderately important to achieve the goals and objectives are achieved there is a match and there are less suitable. Under no circumstances compromise, groups interact with other people trying to achieve the goals , but not as aggressive as in the competitive situation or collaboration. Another opinion stated William states : moderately important when dealing with issues, compromising Often can lead to quick solutions. However, doesnot compromise completely satisfy either party, and compromise does not foster innovation the way that taking the time to collaborate . ( http://www.wright.edu/-scott.williamss/LeaderLetter/conflict.htm ). Weakness compromise conflict management style that is less encouraging people or groups in conflict to try to work hard so that tends to lead to a sense of apathy .

\section{Avoidance ConflictManagement Style}

Avoidance conflict management style is actually less challenging because the leaders are not doing anything to manage conflict. Griffin and Moorhead (2007) states : Avoidance occurs when an interaction is Relatively unimportant to either party 's goals, and the goals are incompatible. It means that avoidance occurs when an interaction is relatively unimportant to the goals of other groups, and even though it is contrary to the goal . Furthermore, Owens (1991) suggested that: Avoidance is useful ( a) when it is not really a likelythat the latent conflict can be resolved ( " live with it") or ( b ) when issues are not so important to the parties as to require time and resources to work them out. In another section, Owens appoint to research's Blake et al that states : avoidance can be in the form of a " cease - fire, " wherein two groups engaged in a long - term struggle decide to keep in contact, still entrenched in their positions, but not to get locked into combat with each other.This suggests that non-urgent avoidance techniques used in managing conflict because it does not produce anything that encourages members to act effectively and productively. This style allows the conflict ignored because it does not interfere with the organization .

\section{Accommodation Conflict Management Style}

Based on the results of data analysis, conflict management style accommodation less intensity or occasionally. This style is considered as a way to most easily done because of trying to please both sides of the conflict. These results are consistent opinion of Griffin and Moorhead ( 2007 ) states : Accomodation Occurs when the goals are compatible, but the interactions are not important to the overall goal Considered Attainment . It means that the accommodation technique occurs when the purpose is appropriate, but the interaction between groups it's not essential in achieving this in line with the goal opinion. Opinion of Wirawan ( 2010) stated that the conflict management style accommodation where low levels of assertive with high cooperation . With this style of someone ignoring the interests of their own destiny and seeks to satisfy the interests of conflict opponents. The argument shows that the technique of accommodation, what matters is the goal is reached and the groups involved in the conflict only agree with what would be achieved. Thus the actual accommodation techniques provide a way out through the middle by accepting all the input / advice from conflicting groups so that all considered to agree .

\section{Conclusion}

Based on the results of research and discussion, it was stated several conclusions: (1) conflict is a situation where there is a conflict between the individual and the individual, the individual with the group and the group with the group; (2) conflict is a phenomenon that always happens in any organization, including the organization of the school; (3) High School Spectrum Manado is a unit of educational organizations and prone to conflicts that require the handling / management of conflict; (4) conflict in general there are two potentially destructive conflict interfere with the performance of the organization and constructive conflict can encourage the emergence of new ideas, innovations; (5) the results showed the five styles of conflict management used principals in dealing conflict at High School Spektrum Manado, namely: competition, collaboration, compromise, avoidance and accommodation. Any two conflict management style most often used in Manado Spectrum High School: Collaboration and Compromise.

\section{References}

[1]. KB Everard, Morris G, Wilson I. 2004. Effective School Management. Fourth Ed . New Delhi: Paul Chapman Publishing

Griffin , Ricky W. and Gregory Moorhead . Organization Behavior . Managing People and

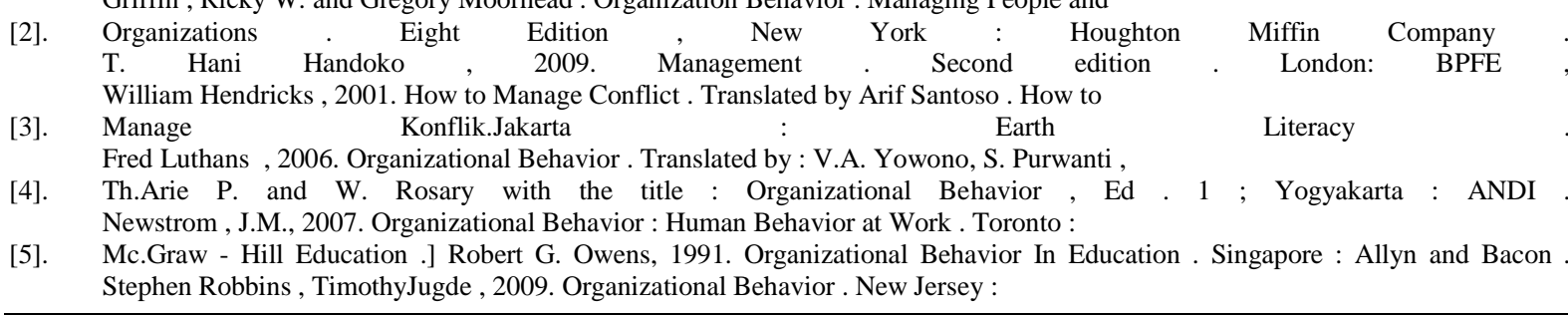


[6]. Pearson Prentie HallSanjaya Wina , 2010. Strategies Learning Process Oriented Education Standards . 7th mold .

[7]. Jakarta : Prenada

John Slocum , Jr. And Don Hellriegel, 2007. Fundamentals of Organizational Behavior.

$\begin{array}{llll}\text { [8]. } & \text { Singapore } & \text { International Student } \\ \text { James Stoner, 1992. Management . Translated by : A. Maulana, Hendardi, Kristina . Jakarta : }\end{array}$

publisher.Supardi , Darwyansyah, Sutomo , Supriyadi E. 2009. Profession of Teaching : competence and Certified . 2nd mold . Jakarta : Diadit Media .

[9]. Wirawan , 2010. Conflict and Conflict Management . Jakarta : Publisher Salemba Humanika.

[10]. http://www.wright.edu/-scott.williamss/LeaderLetter/conflict.htm 